\title{
Prepubertal vulvovaginitis
}

\author{
Emily P.A. Brander MD, Sarah K. McQuillan MD
}

Cite as: CMAJ 2018 July 3;190:E800. doi: 10.1503/cmaj.180004

\section{Inflammation and irritation of the lower genital tract, or \\ 1 vulvovaginitis, is common in prepubertal girls \\ Vulvovaginitis constitutes about $62 \%$ of pediatric gynecologic problems seen in primary care. ${ }^{1}$ Predisposing factors in prepubertal girls (usually defined as age 1-10 yr) include the proximity of the vagina and anus, the absence of protective pubic hair and a lack of labial fat pads.}

\section{Common presenting symptoms include pruritus, discharge, discomfort and dysuria}

Most cases (70\%-80\%) have nonspecific causes ${ }^{1-3}$ and require only reassurance and improved vulvar hygiene (Box 1). It is important to ask about prior episodes, treatments and hygiene habits (toileting, hand washing, tight-fitting clothing and bathing).

\section{3}

\section{About $25 \%$ of vulvovaginitis cases in children are caused by infections}

Bacteria from the gastrointestinal (Escherichia coli) and respiratory tracts ( $\beta$-hemolytic streptococci, Haemophilus influenzae) are the most common culprits. ${ }^{1-4}$ These infections present with pain, erythema and, occasionally, discharge. Vaginitis caused by $H$. influenzae is decreasing with immunization. ${ }^{1}$ Vaginal yeast infections are rare in healthy girls out of diapers. Recent antibiotic use can be a predisposing factor, as can diabetes or immunodeficiency, rarely. Therefore, persistent cases warrant investigation.

Recurrent symptoms, associated with a foul smell, may be due to a foreign body in the vagina

Toilet paper is the most common foreign body found and can be flushed from the vagina with sterile saline. ${ }^{1}$ Otherwise, referral to a gynecologist for vaginoscopy is necessary.

\section{Psoriasis, atopic dermatitis and lichen sclerosus may cause 3 chronic vulvar dermatosis}

Psoriasis presents as red, nonscaly, pruritic plaques, sometimes isolated to the vulva. It is more common in children than adults. ${ }^{1}$ About $15 \%$ of chronic vulvovaginitis in children is due to lichen sclerosis - a paperwhite rash, in a figure-of-eight pattern around the vulva and anus. Both are treated initially with a midpotency topical steroid (e.g., clobetasol propionate $0.05 \%$ ) and a low-potency steroid for maintenance (e.g., hydrocortisone $1 \%)^{1,5}$

\section{Box 1: Tips for vulvar hygiene $e^{1,3}$}

- Removal of irritants: no baby wipes; nylons or tight-fitting clothing; wet bathing suits; bathtubs filled with soap, shampoo or bubble bath; scented detergents; washing powders; or dryer sheets. Sleep in nightgowns or long T-shirts without underwear. All underwear should be dye free.

- Cleaning: Soak the area in warm water for 10-15 minutes per day. Never scrub. Gently wipe front to back with a hypoallergenic soap. Stand up in bath to be soaped, shampooed and rinsed. Let air-dry or gently pat dry.

- Toileting: Lean forward when voiding to prevent pooling of urine in the lower vagina and always wipe front to back.

\section{References}

1. Van Eyk N, Allen L, Giesbrecht E, et al. Pediatric vulvovaginal disorder: a diagnostic approach and review of the literature. J Obstet Gynaecol Can 2009;31:850-62.

2. Stricker T, Navratil F, Sennhauser FH. Vulvovaginits in prepubertal girls. Arch Dis Child 2003;88:324-6.

3. Vilano SE, Robbins CL. Common prepubertal vulvar conditions. Curr Opin Obstet Gynecol 2016;28:359-65.

4. Ranđelović G, Mladenov V, Ristic L, et al. Microbiological aspects of vulvovaginitis in prepubertal girls. Eur J Pediatr 2012;171:1203-8.

5. Fischer GO. Vulvar disease in pre-pubescent children. Australas J Dermatol 2001;42:234-36.

\section{Competing interests: None declared.}

This article has been peer reviewed.

Affiliations: Department of Obstetrics and Gynecology (Brander), McMaster University, Hamilton, Ont.; Obstetrics and Gynecology (McQuillan), University of Calgary, Calgary, Alta.

Correspondence to: Emily Brander, emily. brander@medportal.ca 